\title{
Simulation of Spur Gear for their Nonparallel Axes
}

\author{
Alexandr Shimanovsky 1,* , Dzianis Kuziomkin ${ }^{1}$, Dzmitry Lopukh ${ }^{2}$, Alexander Kovalenko ${ }^{2}$ \\ ${ }^{1 *}$ Belarusian State University of Transport, Kirova 34, Gomel, 246653, Belarus \\ ${ }^{2}$ The State Scientific Institution "Joint Institute of Mechanical Engineering of the National Academy of Sciences of Belarus", Akademicheskaya 12, \\ Minsk, 220072, Belarus
}

\begin{abstract}
The purpose of this work is to analyze the effect of gears with nonparallel axes on the dynamics and loading of gear parts. It was created the algorithm for gear drives modeling considering their non-parallel axes in the MSC.ADAMS package. Simulation demonstrated that the values of the dynamic forces acting the structural parts with constant loading depend on the angle between the shafts axes. The reasons for the high-frequency noise at the gear operation were explained. The results can become a basis for improving the gear drives design, both in terms of improving their reliability and noise reducing.
\end{abstract}

Keywords: spur gear; computer simulation; nonparallel axes; contact forces.

\section{Introduction}

In various machines the most widespread torque transmission is its changing through the gear drives. The advantages of such transmissions are their simplicity of construction and low cost of manufacturing. However, the gears can be a source of harmful vibrations, leading to premature failure of the mechanical systems. Furthermore their operation can lead to a strong noise level which is more higher than the standard values [1].

Theoretically gears with involute profile should maintain a constant angular velocity of the gear and provide a constant tangent interaction force between the teeth of the wheels. But the theory is based on the assumption that the gears are rigid bodies. However, deformation of the material under the applied forces influence, errors in the manufacture and installation of gear wheels, lead to highfrequency vibrations that are the source of noise.

There is a significant number of studies devoted to investigations of the gear drives roughness effect on their dynamic parameters. For example, in the article [2] it is carried out an analysis of gears manufacture errors influence on the smoothness of the transmission by the computer simulation. The authors concluded that the presence of deviations from the parallel working axes leads to the indirect distortion of the involute tooth and causes errors of the transmission step engagement.

In $[3,4]$ the proposal for balancing of inaccurately made wheels by special cargoes were considered for the purpose of mutual compensation of disturbing forces. In the paper [5] there were proposed various ways of reducing gears vibration caused by inaccurate teeth cutting by decreasing the efficiency of oscillations excitation in the low frequency range.

In studies $[6,7]$ there were established the dependences between the parameters of the impact pulse in gearing and vibro-acoustic signal on the gear housing. 
This allowed to identify the level of the gear pair damage at its operation. In paper [8] it is given the method of gear defect determining by means of noise analysis.

In [9] the effect of the stiffness, damping coefficient, gear backlash and other parameters on the dynamic characteristics of the gear pair was investigated. In [10] the dynamic optimization of spur gears was made by a computer model.

Gearing shaft misalignment may be the result of a manufacturing error or gear assembly installation, and may be connected with the design peculiarities of mechanical transmission. Nowadays, the dynamics of gear drives with such abnormalities is studied insufficiently. The purpose of this work is to analyze the effect of gears with nonparallel axes on the dynamics and loading of gear parts.

\section{Computer Models}

As the object of study it was considered a gear with main parameters given in Table 1.

Table 1: Parameters of the driving and driven gears.

\begin{tabular}{|l|c|c|}
\hline Parameter & Driving gear & Driven gear \\
\hline Number of teeth & 14 & 53 \\
\hline Module & 3.5 & 3.5 \\
\hline Pitch diameter, mm & 49 & 185,5 \\
\hline Shift factor & 0.5296 & 0.3204 \\
\hline
\end{tabular}

To create geometric models that differ by various angles between the gears axes it was used a system of three-dimensional solid and surface parametric modeling Autodesk Inventor Fusion. Each model includes a driving and driven gears with the parameters shown in Table 1, which were fixed to the respective shafts. Bearings on the driving shaft have the inner and outer ring diameters of $45 \mathrm{~mm}$ and $85 \mathrm{~mm}$ respectively. Ball-bearings are located on the driven wheel with the inner and outer ring diameter of $75 \mathrm{~mm}$ and $130 \mathrm{~mm}$ respectively. The whole assembled model for the case of parallel axes is shown in Figure 1.

Then the created 3-D model was imported into MSC.ADAMS. The material of details had the properties mentioned in the Table 2.

The connections of bodies interaction in the gear were created in the program. The outer rings of the bearings were rigidly fixed to the ground, the inner ring of the bearing was rigidly attached

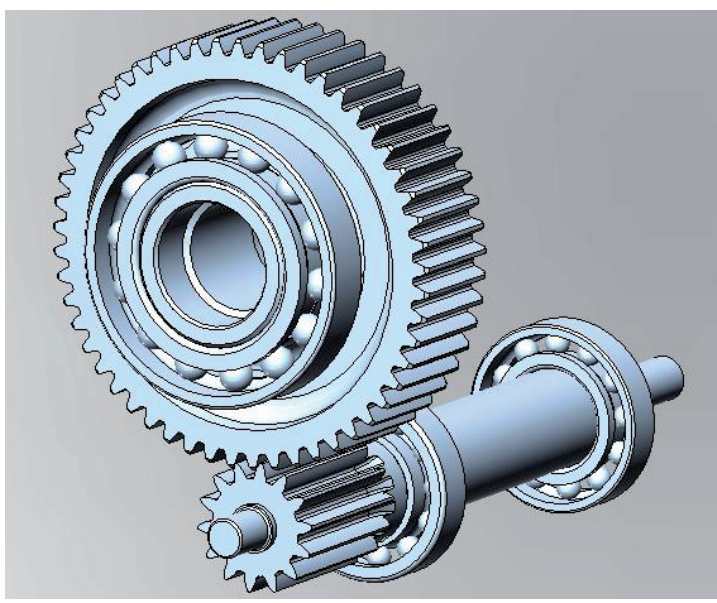

Fig. 1: Model view in Autodesk Inventor Fusion.

Table 2: Material properties.

\begin{tabular}{|l|l|}
\hline Materials & Steel \\
\hline Youngs modulus & $2.07 \mathrm{E}+011$ Newton $/$ meter $^{2}$ \\
\hline Poissons ratio & 0.29 \\
\hline Density & $7801.0 \mathrm{~kg} /$ meter $^{3}$ \\
\hline
\end{tabular}

to the shafts. There were created the contact pairs between the gear wheels and between the ball bearings and the respective outer and inner rings. Interaction forces between the contacting bodies were selected according to the recommendations of $[11,12,13]$ and they are presented in Table 3 .

Table 3: Contact forces properties.

\begin{tabular}{|l|l|}
\hline Contact type (normal force) & Impact \\
\hline Stiffness, N/mm & $1.0 \mathrm{E}+005$ \\
\hline Force exponent & 2.2 \\
\hline Damping, N.s/mm & 10 \\
\hline Penetration depth & 0.1 \\
\hline Static coefficient & 0.3 \\
\hline Dynamic coefficient & 0.1 \\
\hline Static transition velocity & 100 \\
\hline Friction transition velocity & 1000 \\
\hline
\end{tabular}

The calculations of the interaction forces were carried out the formula [7]:

$$
F=\left\{\begin{array}{c}
K\left(x_{0}-x\right)^{e}-C S \dot{x}, \quad x<x_{0} \\
0, \quad x \geq x_{0}
\end{array}\right.
$$


where: $K$ - elastic resistance coefficient (force required to penetrate in the contact area by length unit), $\mathrm{N} / \mathrm{m}^{\mathrm{e}} ; x_{0}$ - the initial position of the center of mass of one contact surface to another; $x$ - the current position of the center of mass of one contact surface to another; $C$ - viscous penetration resistance coefficient of the contact part to another one, N.s/m; e - exponential index of the deformation characteristics; $S$ - step function;

$$
S=\left\{\begin{array}{cc}
0, & x<x_{0} \\
(3-2 \Delta d) \Delta d^{2}, & x_{0}-d<x<x_{0} \\
1, & x \leq x_{0}-d
\end{array}\right.
$$

where: $d$ - the depth of penetration for the maximum value of the viscous resistance, $\mathrm{m} ; \Delta d-$ body deformation;

$$
\Delta d=x_{0}-x
$$

Selection of friction coefficient at each time step was determined according to the translational velocity, as shown in Figure 2. It can be seen that at low velocities, the friction is determined mainly by the static coefficient and increases rapidly with velocity increase. At high velocities, the friction coefficient is determined by a dynamic coefficient and does not practically depend on the velocity.

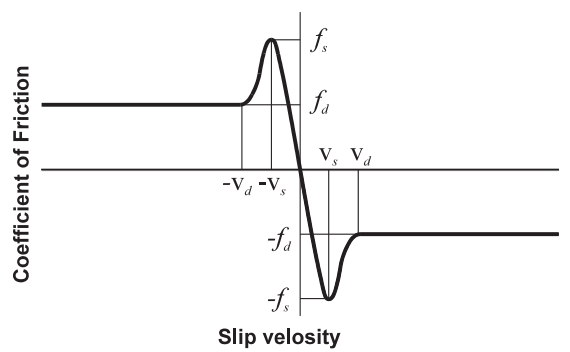

Fig. 2: The dependence between the friction force and the velocity of body movement.

It should be noted that in the original model bearing balls were held only by friction forces. However, the simulation could not be implemented because of the uncertainty at a time when the ball center moved vertically between bearing rings. Therefore, to create a model of the separator in a ball bearing the rolling elements were united by linear springs of $10000 \mathrm{~N} / \mathrm{m}$ stiffness coefficient.

It was assumed that the driving shaft is rotated with a constant angular velocity of $70 \mathrm{rad} / \mathrm{s} . \mathrm{A}$ resistance torque of $100 \mathrm{~N} . \mathrm{m}$ is attached to the driven shaft. The model in MSC.ADAMS package is shown in Figure 3.

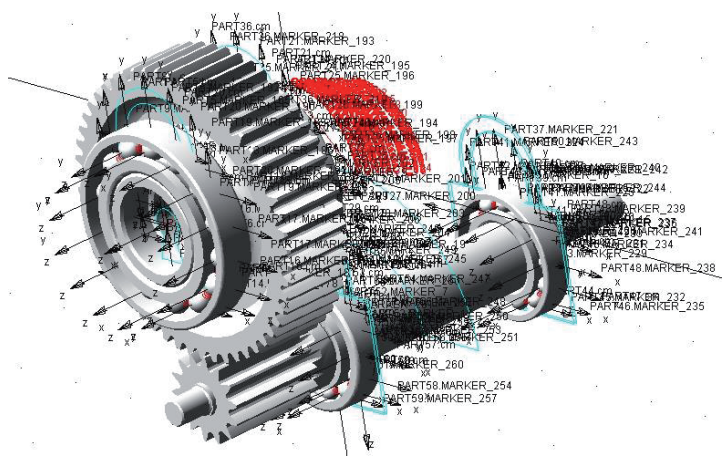

Fig. 3: Model view in MSC.Adams with superimposed connections and forces.

\section{Results and Discussion}

The computations were carried out for a timeperiod corresponding to one revolution of the driving shaft. The time step was assumed to be $0.02 \mathrm{~ms}$. Simulation was performed for a case when shafts axes lied in the same vertical plane and the angle between them was from 0 to $3^{\circ}$.

There were obtained the dependencies of forces, acting the bodies of the system, and kinematic parameters of the units motion on the base the solution of the differential equations system for bodies motion.

Figures 4 - 6 present graphs of changes in the contact forces between the wheels, interaction forces with the outer ring of the bearing and the base and the kinetic energy-time dependence for the $0.5^{\circ}$ angle between the axes of the wheels. These figures show that these factors change with frequency corresponding to a contact time of one teeth pair. Besides, there can be traced high-frequency vibrations at these graphs. Their appearance is connected, from our point of view, first of all, with the presence of the contact pairs. Due to the increase in the number of degrees of freedom caused by contact deformation more natural structure frequencies appear. Periodic effects on body systems related to the entrance of new teeth pairs into the contact, support these oscillations. They are the cause of high-frequency noise that appears at gears operation. 


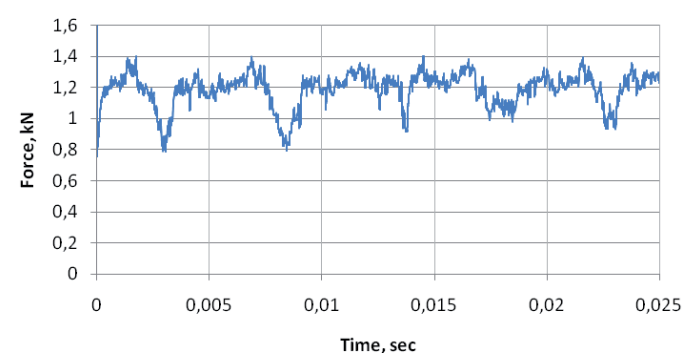

Fig. 4: The dependence of the contact forces between the wheels on the time.

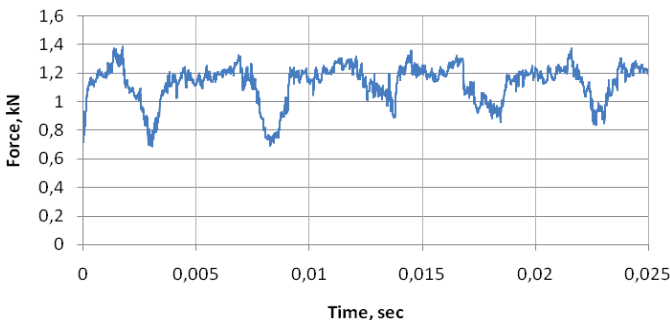

Fig. 5: The dependence of the forces outer ring of the bearing and base on the time.

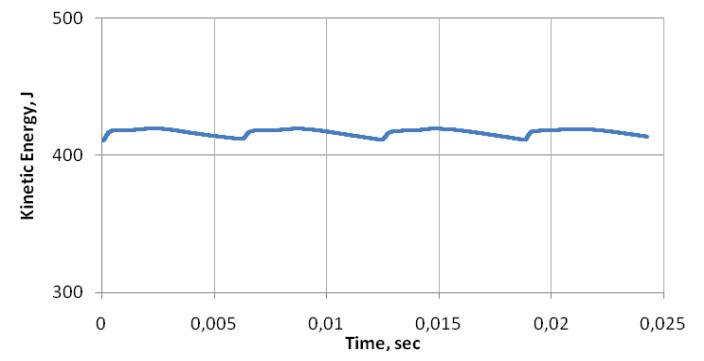

Fig. 6: The dependence of the driven gears kinetic energy on the time.

Figure 7 demonstrates maximal contact force and angle between the shafts dependence. It shows that the force increases monotonically at angle increase. It should be noted that for the parallel shafts a very small change in the gear parameters leads to impacts between the teeth. The values of the impact forces are more than 10 times more than the forces in the unstressed mode (fig 8). If shafts are not parallel, these impacts become weaker.

\section{Conclusions}

Thus, as a result it was created the algorithm for gear drives modeling considering their non-parallel axes in the MSC.ADAMS package. The values of the dynamic forces acting the structural parts with constant loading depend on the angle between

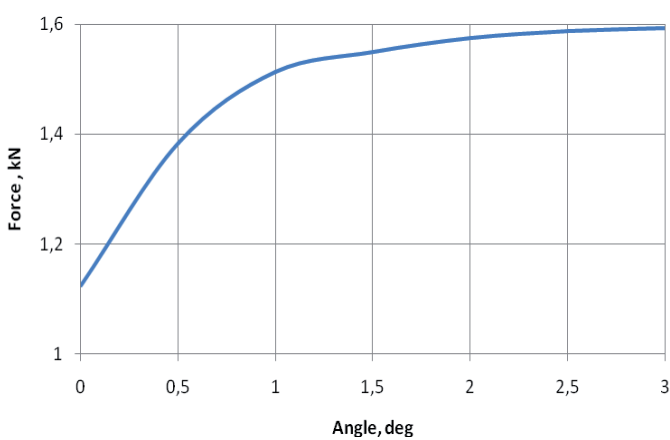

Fig. 7: The dependence of the maximal contact force between wheels on angle between the shafts.

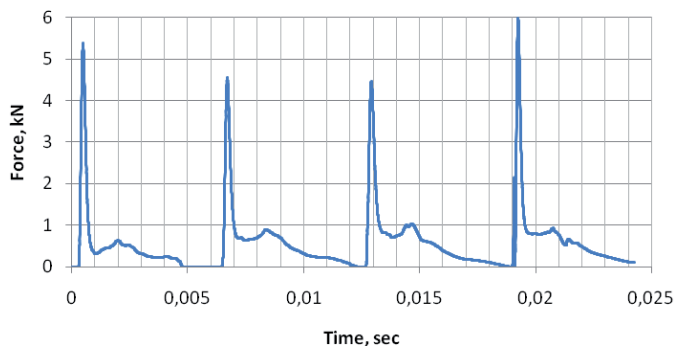

Fig. 8: The dependence of the contact forces between the wheels on the time for teeth impacts.

the shafts axes. The reasons for the high-frequency noise at the gear operation were explained. The results can become a basis for improving the gear drives design, both in terms of improving their reliability and noise reducing.

\section{Acknowledgments}

The work supported by the Belarusian State Program of Scientific Research (Project Mechanics, Technical Diagnostics, Metallurgy 1.32).

\section{References and Notes}

[1] Davis, J. R. (2005). Gear Materials, Properties, and Manufacture. ASM International, Materials Park, 339 p.

[2] Zabelin, D.A. (2008). Investigation of the Errors Gear Wheels Effect on Smooth Operation of Transmission. Journal of Polotsk State University. Series B, Industry. Applied Science, No 2, pages 39-43.

[3] Aparhov, V. I., Glushakov, M. A. (2009). Compensation Methods for Reducing Marine Vibration Activity of Planetary Gears. Technical Acoustics, Vol. 3, No 5, pages 56-59.

[4] Kosarev, O. I. (2001). Driving Forces and Ways to Vibroexcitation Minimize in Spur Gearing. In International Conference Proceeding Modern Information Technology Design and Production of Gears, pages 178-187. 
[5] Aparhov, V. I., Glushkova, M. A. (2011). The fight against lowfrequency vibration of powerful planetary gears. Bulletin of scientific and technological development, No 4, pages 3-7.

[6] Ishin, N. N., Skorohodov, A. S. (2011). Study Parameters of Shock Pulse Gearing Spur Gears. Mechanics of Machines, Mechanisms and Materials, Vol. 4, No 3, pages 19-23.

[7] Ishin, N. N., Goman, A. M., Skorohodov, A. S. (2012). Defining the Parameters of the Shock Pulse Meshed Spur Gears with Take into Consideration of Shafts and Bearings Elasticity. Mechanics of Machines, Mechanisms and Materials, Vol. 3, No 2, pages 37-40.

[8] Kong, D., Meagher, J.M., Xu, C., Wu, X., Wu, Y. (2008). Nonlinear Contact Analysis of Gear Teeth for Malfunction Diagnostics. Mechanical Engineering, Vol. 9, No 2, pages 12-21.

[9] Lu, J., Chen, H., Zeng F., Vakakis, F., Bergman, A. (2014). Influence of system parameters on dynamic behavior of gear pair with stochastic backlash, Meccanica, Vol. 49, No 2, pages 429-440.

[10] Faggioni, M., Pellicanoy, F., Bertacchiz, G., Andrisano, A. O. (2007). Dynamic optimization of spur gears. Proceeding of 12th IFToMM World Congress, pages 18-24.

[11] Polyakov, K. A. (2003). Creation of Virtual Models in MSC.ADAMS Software. University of Samara, Samara City, 89 p.

[12] Hroncová, D., Delyová, I., Frankovský, P. (2014). Kinematic Analysis of Mechanisms Using MSC ADAMS. Applied Mechanics and Materials, Vol. 611, pages 83-89.

[13] Sapietova, A., Saga, M., Hyben, B., Sapieta, M. (2014). Effective methods of parameters refinement of machinery in the program MSC.ADAMS. Applied Mechanics and Materials, No 611, pages 67-74.

\section{Biographical notes}

Alexandr Shimanovsky: doctor of engineering sciences, associated professor (born in 1963) graduated from Belarusian Institute of Railway Transport Engineers in 1985. Now he is head of Technical physics and engineering mechanics department, Belarusian State University of Transport, Gomel, Belarus. His professional activity is focused on computer and analytical modeling of dynamics and strength of machine and construction. Since 2005 he has held the International Engineering Mechanics Contest for University students. He is co-author of 2 monographs, 11 university text books and more than 120 works published in journals, conference proceedings in Belarus, Russia, Ukraine and other countries. He participates in the solving a several state projects and different tasks in cooperation with the practice.

Dzianis Kuziomkin: (born in 1989) graduated from Belarusian State University of Transport, Gomel, Belarus in 2013. Now he is Postgraduate student of Part of machine, track and construction machinery department, Belarusian State University of Transport. His scientific activity is focused on modeling of machine and mechanisms dynamics. Also he works as teacher in further training educational institution. He is co-author of more than 10 works published in journals and conference proceedings in Belarus.
Dzmitry Lopukh: (born in 1981) graduated from Belarusian State Agrarian Technical University, Minsk, Belarus in 2013. Now he is Section head in The State Scientific Institution "Joint Institute of Mechanical Engineering of the National Academy of Sciences of Belarus", Minsk. His professional activity is mainly focused on mechanics of mobile machine. He is also interested in computer modeling of various mechanical systems. He is co-author of 2 university text books and more than 15 papers published in journals, conference proceedings mainly in Belarus. Also he is co-author of 20 patents and 10 specialized computer programs. He participates in the solving of different tasks in cooperation with the practice.

Alexander Kovalenko: PhD, associated professor (born in 1977) graduated from Belarusian State University of Transport in 2001. Now he is Scientific Secretary in The State Scientific Institution "Joint Institute of Mechanical Engineering of the National Academy of Sciences of Belarus," Minsk. Before 2011 he was an associated professor of Technical physics and engineering mechanics department, Belarusian State University of Transport, Gomel, Belarus. His professional activity is mainly focused on dynamics of railway vehicles. He is co-author of 2 university text books and more than 25 papers published in journals, conference proceedings mainly in Belarus and 4 patents. He participates in the solving a several state projects 